\title{
A study on the properties Synthesis, Growth, spectral, structural, optical thermal studies of a new organic crystal and NLO applications of $\mathrm{N}$-( tert- butyl)-4-(nitrophenyl imidazo [1,2-a]pyrazin-3-amine
}

\author{
K.Elumalai Kuppan ${ }^{1} *$ K.Sakthiumurugesan ${ }^{2}$ \\ ${ }^{1}$ Department of physics, presidency college (Autonomous),Chennai, India \\ ${ }^{2}$ Department of physics, presidency college (Autonomous),Chennai, India
}

Corresponding author: elumalai9176@gmail.com

Available online at: www.isroset.org

Received 20/Dec/2017, Revised 14/Jan/2018, Accepted 25/Feb/2018, Online 30/Apr/2018

\begin{abstract}
In this work, an organic crystal ,synthesis of N-(tert-butyl)-2-(4-nitrophenyl)imidazo[1,2-a]pyrazin-3-amine.vibration modes were assigned using FT-IR and FT-Raman spectra Raman spectra correlate very well with the structural data and illustrate the subtitle choice of the ligands, used can affect the vibrational characteristics of the Mo-o bonds Fourier Transform Infrared (FT-IR) spectral studies have been carried out, to confirm the presence of various functional group .The UV-Vis-NIR spectrum suggests the suitability of crystal for various optical application properties were investigated using the result of UV-Vis study showed that the crystal was about 50\% transparent in the visible region. The grown crystal exhibits some excellent characteristics including wide optical transparency in the region (210-1100nm).ultraviolet wavelength emission .The optical transmittance of the crystal was ascertained by recording Mass spectroscopy. TGA/DSC analysis. Third order optical properties nonlinear absorption coefficient. non-linear refractive index and third order non-linear susceptibility was calculated by z-scan method using $632.8 \mathrm{~nm}$ He-Ne laser. The thermo gravimetric Analysis (TGA) and Differential Scanning Calorimeter (DSC) were carried out to establish the thermal stability of the crystal .The $1 \mathrm{H}$ and $\mathrm{C} 13$ nuclear magnetic resonance spectra were recorded to establish the molecular structure of the crystal. The crystal structure was confirmed by Single Crystal x-ray diffraction.
\end{abstract}

Keywords- Crystal structure, FTIR, Differential Scanning calorimeter, Thermo gravimetric Analysis ,NMR, ,Third harmonic Generation, Raman Spectroscopy, UV- vis -NIR spectrum, Mass spectroscopy

\section{INTRODUCTION}

The organic material organic systems have been extensively attracting candidate used in the synthesis of efficient second and TONLO materials due to its quick NLO response with the enhanced figure of merit. In this particular organic ionic crystals have lead high resolution because of its electro delocalization behaviour inherent facile synthetic flexibility second harmonic generation efficiency with large LDT value wide optical transparency high. Thermal stability FT-IR and FT-Raman mechanical thermal, third order nonlinear optical properties of pzno2 crystals .SHG materials are much warranted because of their potential applications in the field of optoelectronics. The title materials was synthesized and the single crystals were grown and characterized through electronic, vibrational, absorptions, nuclear magnetic resonance spectral studies and TGA/DSC and nonlinear optical studies. In this paper for the first time we report the synthesis, growth, structural and physical properties of the title crystal pyrazin-3-amine.

\section{EXPERIMENTAL PROCEDURE}

synthesis of $\mathrm{N}$-(tert-butyl)-2-(4-nitrophenyl)imidazol[1,2-a]pyrazin-3-amine: $\mathrm{pzno}_{2}$ 4-nitro benzaldehyde (1mmol),2-Amino pyrazine $(1 \mathrm{mmol})$, tertiary butyl isocyanide $(1 \mathrm{mmol})$ and ethanol $(8 \mathrm{ml})$ were added to $50 \mathrm{ml} \mathrm{RB}$ flask. The reaction mixture 
was stirred at room temperature with catalytic amount of Iodine for about 24 hours .An orange-yellowish solvents. The precipitate was filtered off, washed with excess ethanol and dried under vaccum. Finally collected the precipitated and crystallized from ethanol to get $98 \%$ yield and check the further spectrum data analysis.

\section{Single crystal X-Ray diffraction analysis}

Single crystal of compound suitable for X-ray diffraction was obtained by slow evaporation method. Three dimensional intensity data were collected on the BRUKER6 SAMRT APEX CCD diffractometer using graphite monochromatized MO-KX radiation $(=0.71073 \mathrm{~A})$.The structure was solved by direct method and refined of $\mathrm{F} 2$ by full-matrix least-squares procedures using the SHELXL programs7, All the non-hydrogen atoms were refined using isotropic and later anisotropic thermal parameters. The hydrogen atoms were included in the structure factor calculation at idealized position by using a Single crystals suitable for X-ray crystallographic analysis were selected following an examination under a polarizing microscope. The title crystal belongs to triclinic crystallographic system with non-centrosymmetry space group c1c1.The cell parameters are $\mathrm{a}=16.0877(10) \mathrm{A}, \mathrm{b}=22.0452(13) \mathrm{A}, \mathrm{c}=17.8670(11) \mathrm{A}$, The intermolecular N-H-O,O-H-O and C-H-O Type hydrogen bonds between the cationic anionic species help to create a delicate balance between the molecular figure 1 shows the ORTEP of the molecule drawn at $40 \%$ probability thermal displacement ellipsoids with the atom numbering scheme.

Table-1- Crystal data and structure refinement of pzno $_{2}$

\begin{tabular}{|c|c|c|}
\hline Chemical formula & \multicolumn{2}{|l|}{$\mathrm{C}_{16} \mathrm{H}_{17} \mathrm{~N}_{5} \mathrm{O}_{2}$} \\
\hline Formula weight & \multicolumn{2}{|l|}{$311.34 \mathrm{~g} / \mathrm{mol}$} \\
\hline Temperature & \multicolumn{2}{|l|}{$296(2) \mathrm{K}$} \\
\hline Wavelength & \multicolumn{2}{|l|}{$0.71073 \AA$} \\
\hline Crystal size & \multicolumn{2}{|c|}{$0.100 \times 0.220 \times 0.250 \mathrm{~mm}$} \\
\hline Crystal habit & \multicolumn{2}{|c|}{ clear light yellow Block } \\
\hline Crystal system & \multicolumn{2}{|l|}{ Triclinic } \\
\hline Space group & \multicolumn{2}{|l|}{$\mathrm{P}-1$} \\
\hline \multirow[t]{3}{*}{ Unit cell dimensions } & $a=7.1624(5) \AA$ & $\alpha=112.236(4)^{\circ}$ \\
\hline & $\mathrm{b}=10.6301(9) \AA$ & $\beta=96.322(3)^{\circ}$ \\
\hline & $\mathrm{c}=11.2949(8) \AA$ & $\gamma=93.655(4)^{\circ}$ \\
\hline Volume & $785.96(10) \AA^{3}$ & \\
\hline $\mathrm{Z}$ & \multicolumn{2}{|l|}{2} \\
\hline Density (calculated) & \multicolumn{2}{|l|}{$1.316 \mathrm{~g} / \mathrm{cm}^{3}$} \\
\hline Absorption coefficient & \multicolumn{2}{|l|}{$0.091 \mathrm{~mm}^{-1}$} \\
\hline $\mathrm{F}(000)$ & \multicolumn{2}{|l|}{328} \\
\hline Theta range for data collection & \multicolumn{2}{|l|}{1.97 to $24.99^{\circ}$} \\
\hline Index ranges & \multicolumn{2}{|c|}{$-7<=\mathrm{h}<=8,-12<=\mathrm{k}<=11,-13<=1<=13$} \\
\hline Reflections collected & \multicolumn{2}{|l|}{6715} \\
\hline Independent reflections & \multicolumn{2}{|c|}{$2298[\mathrm{R}$ (int) $=0.0319]$} \\
\hline Coverage of independent reflections & \multicolumn{2}{|l|}{$82.9 \%$} \\
\hline Absorption correction & \multicolumn{2}{|l|}{ multi-scan } \\
\hline Max. and min. transmission & \multicolumn{2}{|l|}{0.9910 and 0.9780} \\
\hline Refinement method & \multicolumn{2}{|c|}{ Full-matrix least-squares on $\mathrm{F}^{2}$} \\
\hline Refinement program & \multicolumn{2}{|c|}{ SHELXL-2014/7 (Sheldrick, 2014) } \\
\hline Function minimized & \multicolumn{2}{|l|}{$\sum \mathrm{w}\left(\mathrm{F}_{\mathrm{o}}{ }^{2}-\mathrm{F}_{\mathrm{c}}{ }^{2}\right)^{2}$} \\
\hline Data / restraints / parameters & \multicolumn{2}{|l|}{$2298 / 0 / 216$} \\
\hline Goodness-of-fit on $\mathrm{F}^{2}$ & \multicolumn{2}{|l|}{1.010} \\
\hline \multirow[t]{2}{*}{ Final $\mathrm{R}$ indices } & 1451 data; $I>2 \sigma(I)$ & $\mathrm{R} 1=0.0479, \mathrm{wR} 2=0.1117$ \\
\hline & all data & $\mathrm{R} 1=0.0863, \mathrm{wR} 2=0.1324$ \\
\hline Weighting scheme & \multicolumn{2}{|c|}{$\begin{array}{l}\mathrm{w}=1 /\left[\sigma^{2}\left(\mathrm{~F}_{\mathrm{o}}^{2}\right)+(0.0632 \mathrm{P})^{2}+0.1454 \mathrm{P}\right] \\
\text { where } \mathrm{P}=\left(\mathrm{F}_{\mathrm{o}}^{2}+2 \mathrm{~F}_{\mathrm{c}}^{2}\right) / 3\end{array}$} \\
\hline Extinction coefficient & \multicolumn{2}{|l|}{$0.0080(30)$} \\
\hline
\end{tabular}




\begin{tabular}{|l|l|}
\hline Largest diff. peak and hole & 0.196 and $-0.141 \mathrm{e}^{-3}$ \\
\hline R.M.S. deviation from mean & $0.039 \mathrm{e}^{-3}$ \\
\hline a) & b) \\
\hline
\end{tabular}

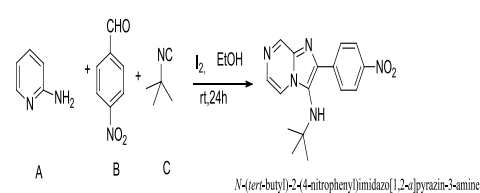

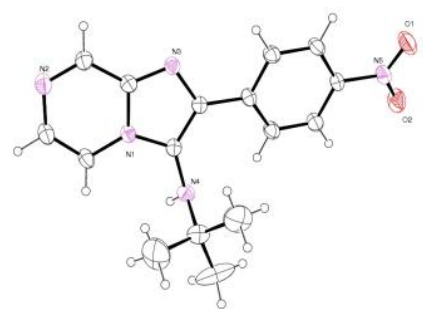

d)
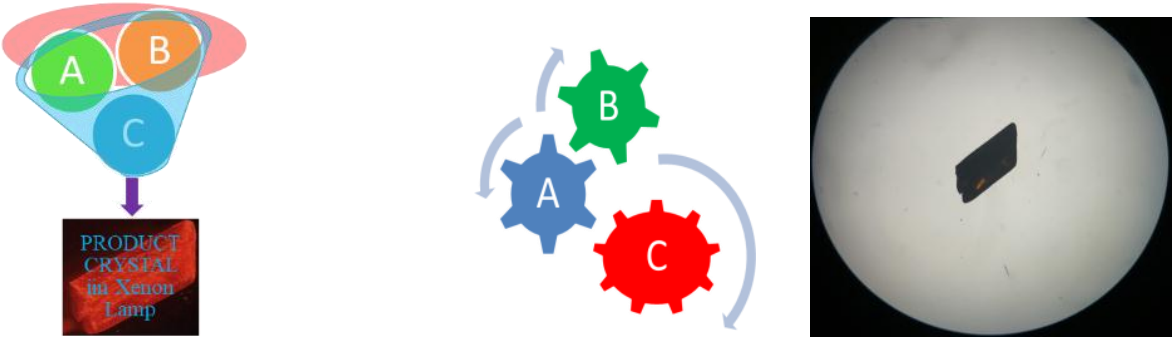

Figure 1.a) Reaction scheme, b) ORTEP view of crystal c) Crystal in Xenon lamp

d) Crystal in ordinary light

\section{FT-IR}

The FT-IR spectrum is recorded in the range $400-4000 \mathrm{~cm}^{-1}$ by Perkin-Elmer spectrometer FT-IR spectrum of pzno 2 is given in figure .

a)

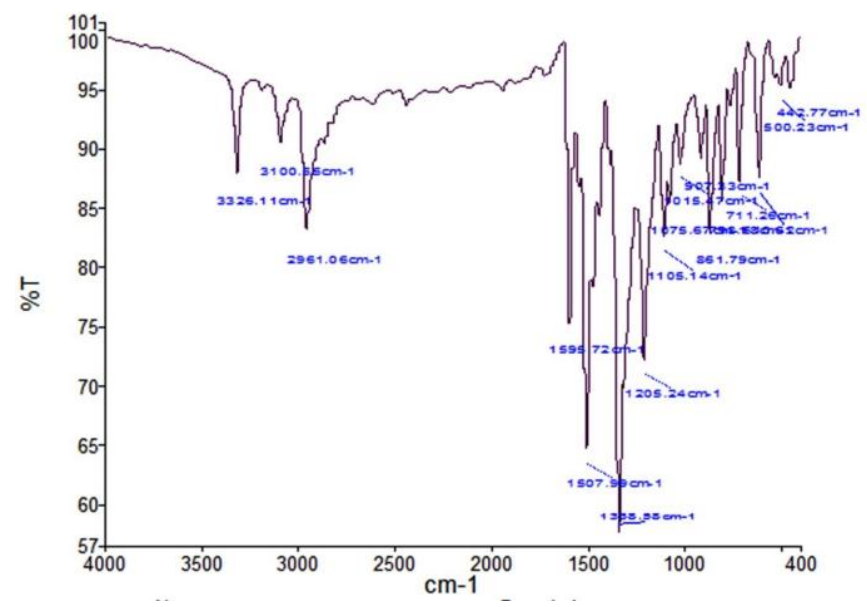

b)

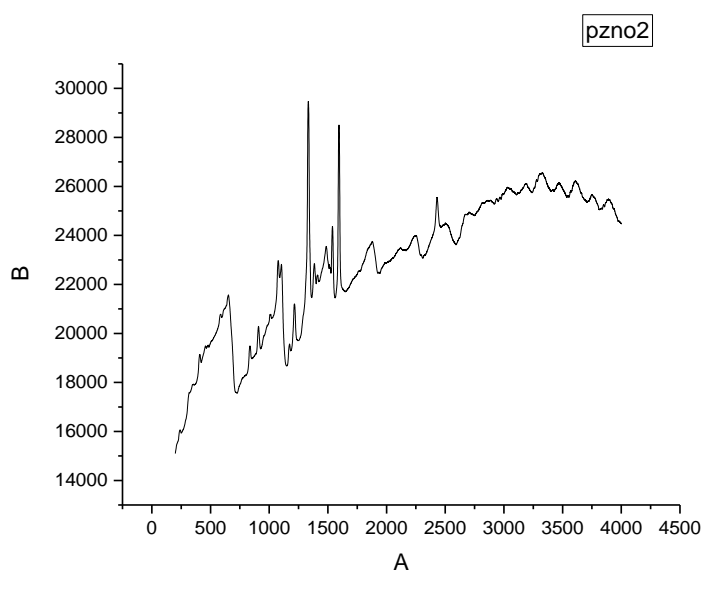


c)

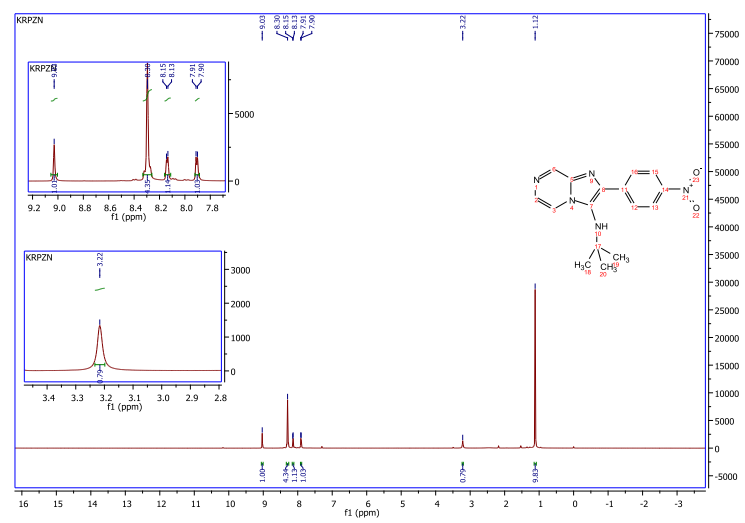

e)

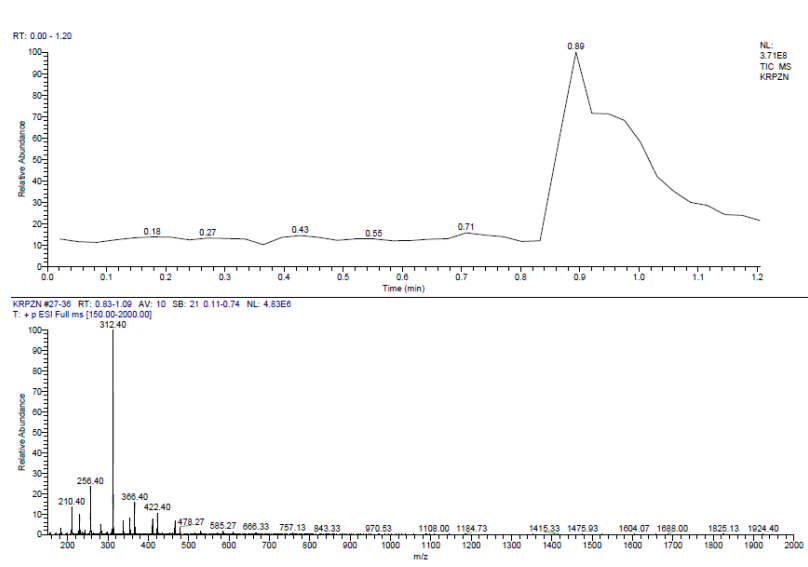

d)

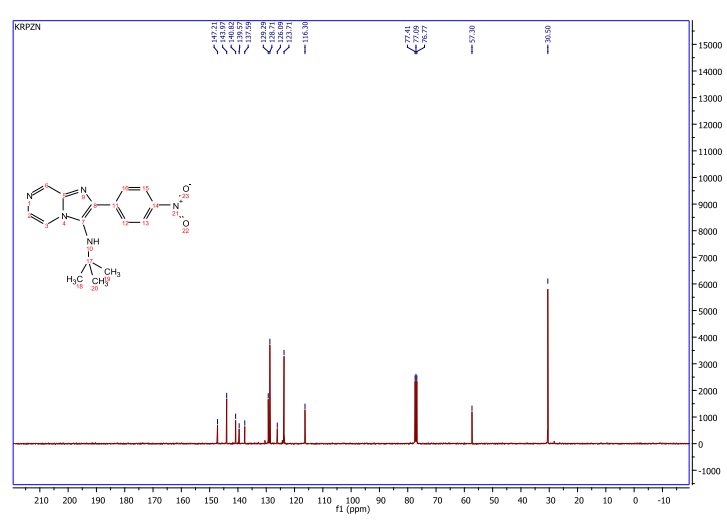

f)

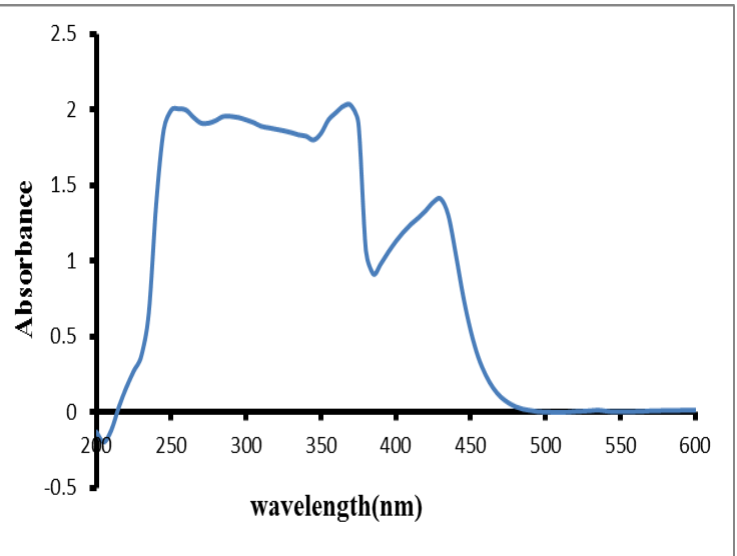

Figure.2.a-f) FT-IR spectrum, Raman spectrum, $\mathrm{H}^{1}$ NMR, $\mathrm{C}^{13} \mathrm{NMR}$, Mass spectrum, UV-Visible spectrum

\section{NMR spectral studies}

From nmr studies we have to confirm the product of the structure from the following H1 and C13 peaks values

${ }^{1} \mathrm{H}$ NMR $\left(400 \mathrm{MHz}, \mathrm{CDCl}_{3}\right) \delta 9.03(\mathrm{~s}, 1 \mathrm{H}), 8.30(\mathrm{~s}, 4 \mathrm{H}), 8.14(\mathrm{~d}, J=4.4 \mathrm{~Hz}, 1 \mathrm{H}), 7.91(\mathrm{~d}, J=4.5 \mathrm{~Hz}, 1 \mathrm{H}), 3.22(\mathrm{~s}, 1 \mathrm{H}), 1.12$ (s, 9H).

${ }^{13} \mathrm{C}$ NMR $\left(101 \mathrm{MHz}, \mathrm{CDCl}_{3}\right) \delta 147.21,143.97,140.82,139.57,137.59,129.29,128.71,126.09,123.71,116.30,77.41,77.09$, $76.77,57.30,30.50$

\section{Mass Spectroscopy}

Mass spectroscopy characterization is an important study for NLO crystals to know the optical the transmission range of the crystals .The grown crystals of pzno2 were subjected to absorption -transmission measurements in the spectral. region of 190$1100 \mathrm{~nm}$ using the T+PESI full Mass spectroscopy. The transmission spectrum for pzno2 crystal . Expected mass 311.34.Observed mass is 312.40

\section{UV-Visible spectrum}


From the UV-vis -NIR transmission spectrum (figure. 2(f), it is observed that there is no significant absorption in the entire visible and infrared regions enabling the title crystal to be a most suitable candidate for various optical applications. The attained percentage of transmittance is $85 \%$ in the visible region. The lower wavelength cut off is around $430 \mathrm{~nm}$. The good transmittance coupled with very low wavelength cut off ensures its suitability for second harmonic generation applications. The lower cut-off wavelength and high optical transparency up to near infrared region are crucial parameters for an optical material. UV-Vis-NIR spectrum was recorded within the range of 200-1100 nm using varian. cary 5000model spectrophotometer. It was observed from the UV-Vis-NIR. It absorbs at $430 \mathrm{~nm}$ and $285 \mathrm{~nm}$ EtOH solvent used $10 \mathrm{Um}$ concentration of sample per $\mathrm{mL}$

\section{Thermo gravimetric analysis}

Thermo analysis was performed of the grown crystal to study the thermal stability and melting point. The thermo gravimetric analysis of LHFFA Was carried out between room temperature .The TGA and measurements show the mass variation recorded during the heating. The results are shown in figure The obtained TGA curves shows. sudden weight loss at $228.29^{\circ} \mathrm{c}$ a power sample weighing $24 \mathrm{mg}$ was used for the analysis. The analyses were carried out simultaneously in air at a room of 0 $100^{\circ} \mathrm{c}$ and are represented in figure. The thermo gravimetric analysis shows that the sample has good thermal stability up to $180^{\circ} \mathrm{c}$.The absence of water of crystallization in the molecular structure is indicated by the absence of weight loss around $100^{\circ} \mathrm{c}$ further there is no decomposition up to the melting point. The material decomposes at $228.29^{\circ} \mathrm{C}$ which represented by the students of loss of the mass. above $228.29^{\circ} \mathrm{c}$ the undergoes invertible endothermic transition at $338.99^{\circ} \mathrm{c}$. The thermo gravimetric ( $\mathrm{tg}$ ) were carried out in a nitrogen atmosphere from room temperature to $773 \mathrm{k}$. The decomposition occurs in two stages. The first stage incurred weight loss $10.34 \%$ at $338.99{ }^{\circ} \mathrm{C}$ and the second stage of $97.05 \%$. The sharp exothermic peak $228.29^{\circ} \mathrm{c}$ corresponds to the melting point of the substance. Thermal analysis was performed on the frown crystal to study the thermal stability and melting point. The thermo gravimetric analysis of LHFFA was carried out between room temperature (28c) and $1200^{\circ} \mathrm{c}$ heating rate $20 \mathrm{c} / \mathrm{min}$ in nitrogen atmosphere using SDT Q $6000 \mathrm{~V} 8.2$ built 100 thermal analyzer.

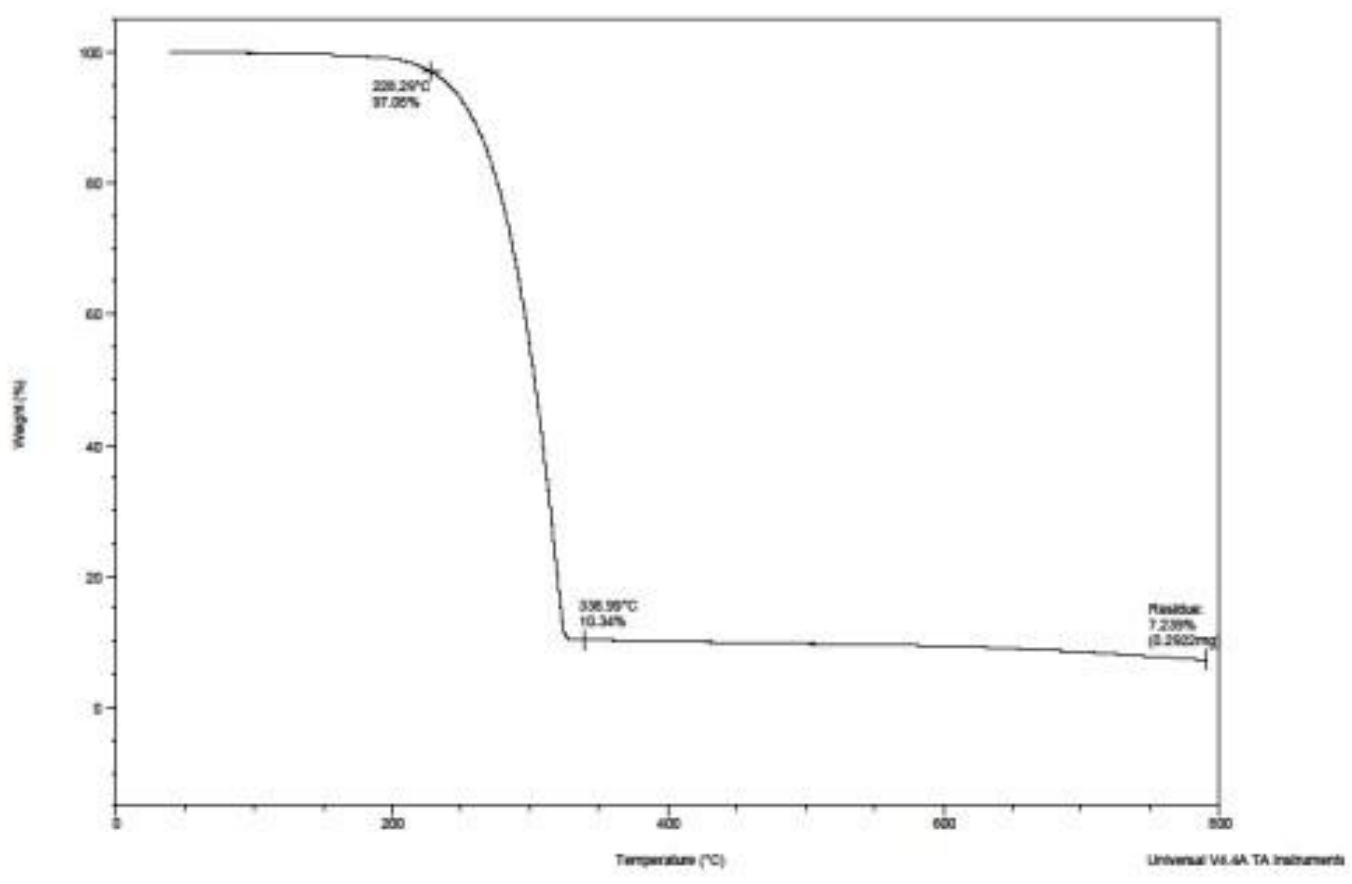

Figure3: Thermo gravimetric analysis curve of crystal pzno2 


\section{Third order nonlinear optical properties}

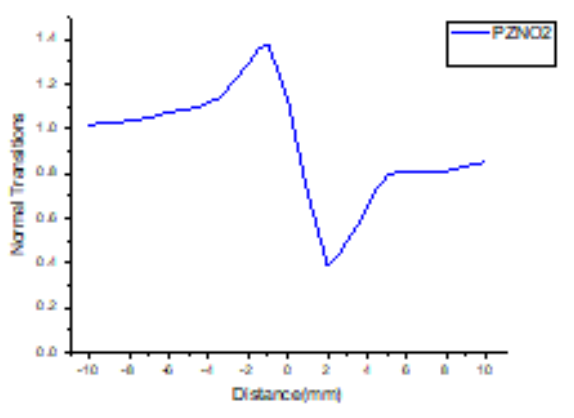

Figure 5a:Z-scan of closed curve

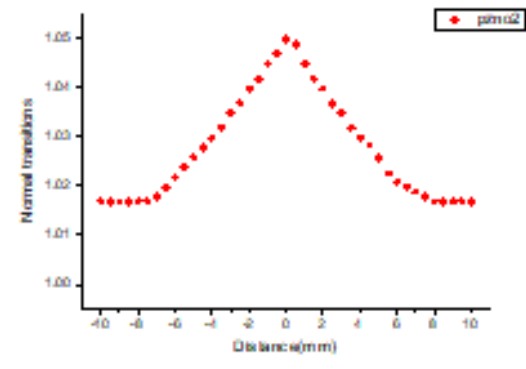

Figure $5 \mathrm{~b}: \mathrm{Z}$-scan of opened curve

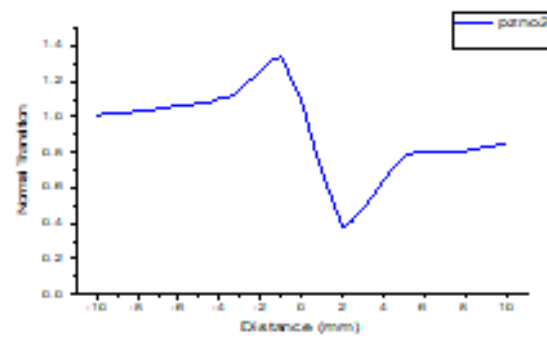

Figure 5c: Z-scan of Ratio curve

Figure 4: z-scan Third order nonlinear optical properties

The third order nonlinear refractive index and the nonlinear absorption coefficient were evaluated by the $\mathrm{z}$ scan measurements. In this method the sample is translated in $\mathrm{z}$ direction along the axis of a focused gaussian beam from the He-Ne laser at $\lambda=$ $632.8 \mathrm{~nm}$ and the far field intensity is measured as a function of the sample position. It allows the simultaneous measurements of both the nonlinear refractive index and the nonlinear absorption coefficient .non-linear refractive index $\mathrm{n}_{2}$ was calculated by

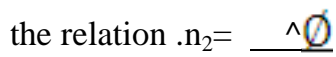

KI ${ }_{\mathrm{o}}$ left where $\mathrm{k}$ is wave vector, Io is intensity of the laser beam at focus $(\mathrm{z}=0)$ left is affective thickness of the material and $\wedge \emptyset$ is phase shift.

The nonlinear absorption coefficient was estimated from the open aperture z-scan data using the relation. $\beta=2 \sqrt{2} x \mathrm{~T}$ Io left

where $\triangleq \mathrm{T}$ is one valley value at open aperture $\mathrm{z}$-scan curve. The read and imaginary parts of the third order nonlinear susceptibility are defined as,

$\operatorname{Re} \mathrm{X}^{(3)}=\underline{10^{-4} \mathrm{\epsilon O}^{2} \mathrm{no}^{2} \wedge \emptyset}$

$\pi$

$\mathrm{I}_{\mathrm{m}}(\mathrm{x})^{3}=\frac{10^{-2} \epsilon \mathrm{O} \mathrm{c}^{2} \mathrm{no}^{2} \quad \beta}{-4 \pi^{2}}$ 
where $\underline{\epsilon 0}$ is premitivity of the vacuum, no is linear refractive index of the material and $\mathrm{c}$ is velocity of light $\mathrm{X}^{(3)}$ $=\sqrt{ }\left[\operatorname{Re}\left(\mathrm{X}^{(3)}\right]^{2}+\left[\operatorname{lm}\left(\mathrm{x}^{(3)}\right]^{2}\right.\right.$

closed aperture and open aperture z-scan curves are given in fig. from the closed aperture z-scan measurements ,the nonlinear refractive index was calculated as $7.658 * 10-{ }^{8} \mathrm{~cm}^{2} / \mathrm{W}$. The positive value of nonlinear refractive index shows that the crystal has a self-focusing nature, open aperture z-scan measurements concluded that the nonlinear absorption co-efficient of the material is

$0.037 * 10^{-4} \mathrm{Cm} / \mathrm{W}$.The third order nonlinear susceptibility $\mathrm{x}{ }^{(3)}$ was calculated as $2.142 * 10^{-6}$ esu. The calculated third order non-linear optical values of $\mathrm{pzno}_{2}$

\section{Third order non-linear optical values of pzno $_{2}$}

Non-linear Refractive index $\mathrm{n} 2(\mathrm{~cm} 2 / \mathrm{w}) 7.658 * 10^{-8}$

Real part of susceptibility Re

$\mathrm{x}(3)$ (esu) $\quad 2.130 * 10-6$

Third order susceptibility X(3) (esu)

$\mathrm{x} 3$ values of some NLO crystals

crystal

$\mathrm{Pzno}_{2}$ non-linear absorption coefficient, $\mathrm{b}(\mathrm{cm}$

/w) $0.037 * 10-4$

Imaginary part of susceptibility Im

$\mathrm{x}(3)$ (esu) $0.229 * 10-6$

$1.048 * 10-3$

$\mathrm{x}(3)$ (esu)

$2.142 * 10-4$

He-Ne laser ( $5 \mathrm{mw})$ source of wavelength $(\lambda=632.8 \mathrm{~nm})$ with the beam diameter of $0.5 \mathrm{~mm}$ was used for the Z-scan experiment. The Gaussian input laser beam generated by focusing via gaussian filter was projected through a convex lens placed at a focal length of $30 \mathrm{~mm}$ in transverse mode operation. High power laser damage tolerance factor decides the performance of an optical material to be employed in laser power related device applications.

\section{Differential scanning calorimeter}

The differential scanning calorimeter `is carried out using SDT Q200 V23.10 build 79 analyser between 50 and $300{ }^{\circ} \mathrm{c}$ in the nitrogen atmosphere at a heating rate of $50{ }^{\circ} \mathrm{c} / \mathrm{min}$ and its shown in figure. In the dsc the endothermic peak observed near $33^{\circ} \mathrm{c}$ corresponds to melting and In the differential thermo gram, one sharp exothermic . The first stage, a 55\% of weight loss of observed between $64.29 \mathrm{c}$ and85.18c , which might be due to the decomposition of fumaric acid in pzno2 crystal. The second stage of decomposition with $100 \%$ of weight loss appeared $80.21 \mathrm{c}$, which was attributed to the liberation of creatinine moiety and remaining volatie substances. 


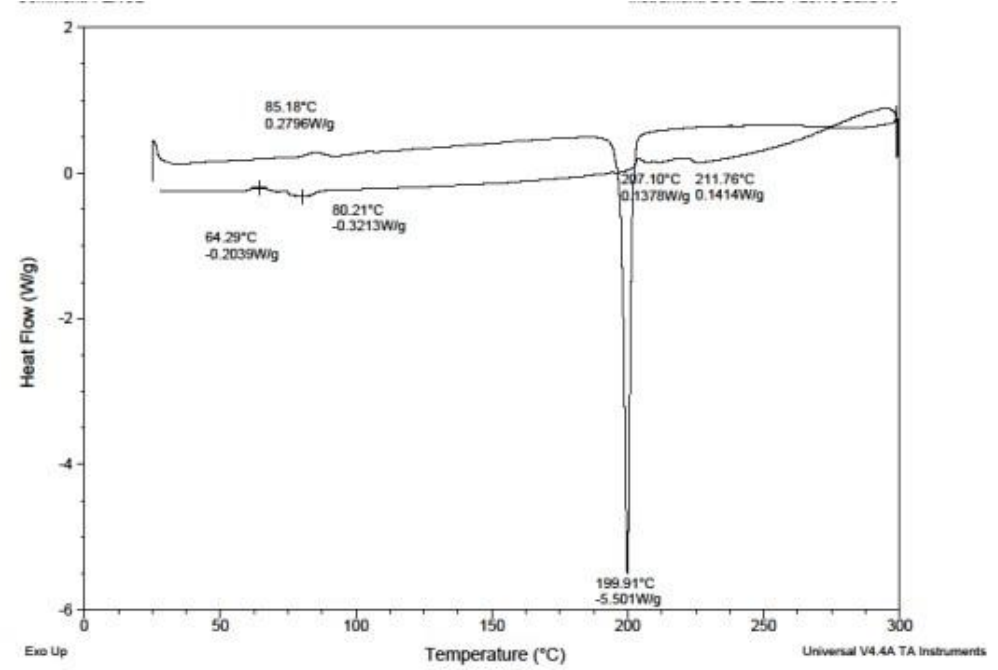

Figure 5: Differential Scanning Calorimetry curve of pzno2 crystal

\section{RAMAN SPECTROSCOPY:}

Raman spectrum of pzno2 crystal are recorded using BRUCKER RFS 27 FT-Raman spectrometer with Nd:YAG, laser (1064 $\mathrm{nm}$ ) sample was scanned over the range of $500-400 \mathrm{~cm}-1$. The recorded FT-Raman spectrum is shown in figure peak observed for a given energy of the laser beam, the strength of Raman scattering depends on (frequency) and it was for this reason that lasers in the high-frequency, visible end of the spectrum were formely used. more recently, however ,near-infra-red laser excitation has been successful, usually using Nd: YAG laser operating at $9398 \mathrm{~cm}-1$. Thus the structures of these molecules are completely determined.

\section{CONClusion}

The molecular structure was established by single crystal XRD analysis and further confirmed by NMR spectroscopic study. The presence of various functional groups in the title salt has been confirmed by FT-IR spectrometer Study. These crystals were subjected into various characterizations. single crystal XRD analysis shows that pzno2 crystal belong to triclinic crystal system with lattice parameters $a=7.16249(5) \mathrm{A}, \mathrm{b}=10.6301(9) \mathrm{A}, \mathrm{C}=11.2949(8) \mathrm{A}$. Single crystal X-ray studies confirmed the cell parameters of pzn02 crystal. Which can be employed in the NLO 'Applications in the entire visible region. The Mass spectroscopy visible spectrum reveals that the grown crystals have the cut-off wavelength of 430 and $285 \mathrm{~nm}$, which can be employed in the NLO applications in the entire visible region and the near mass spectroscopy and the near IR region. The The functional groups are assigned using FT-IR and FT-Raman spectroscopy. In UV-visible spectral analysis, the cut off wavelength was found to be $396 \mathrm{~nm}$. The UV -Vis-NIR spectrum suggests the suitability of crystal for various optical application. Thermo gravimetric and differential thermal analysis shows that the crystal is stable up to 200c. The order nonlinear optical properties are calculated using Z-scan technique. The recorded FT-IR spectrum confirms the presence of various functional groups as well as existence of inter-molecular hydrogen bonding between the constituent species. The thermal behaviour of the grown crystal was studied by TGA-DSC analyses. The single and multiple shorts laser damage threshold values and the relative SHG efficiency of pzn02 were found out.

\section{REFERENCES}

[1]B.N. Brown. Act a crystallogr.14 (1961) 711-715

[2]Kurtz sk. perry TT.J. Appl. physics 1968:39:3798

[3]parsons .s., Flack. H.D\& Wagner, T.(2013). Acta Cryst. B69,249-259

4]J.W. Johnson A.J. Jacobson. s. m Rich J.F. Brody J.AM. chem. soc 103 (1981)5246-5247 
[5]J.T. Lin W.S. Wang. H. Arend proc SPIE 1104(1989) 100

[6]P.N. Prasad .D.J. Williams, Introduction to NLO Effects in molecules and polymers, wiley, new York-1991

[7]B. E. A. Saleh. M.C. Tech Fundamentals of photonics, wiley, New York-1991

[8]Y.Z. Zhou E.B. Wang. J. Liu C.W.HU.R.D. Huang X.YOU polyhedron 18 (1999)1419-1403

[9]H.O. Marcy L.F Warren M.S Webb C.A. Ebbers, S.P. Velsko G.C. Kennedy, G. C, Catella.Appl.opt.31(1992)5051-5060.

[10]Min-huajiangqi Fang. Adv. marcen, M. kollmanns berger, o. Lavast E.fresh,J.F.Letard,o.kahh,chem.phys.Lett.324(2000)321-329

[11] Gompper R, Mehrer, M polbornk.9,10 Bis (4,5 diphenylimidazol-2-yliden)-9-,10-dihydro an thracene-A folded-quinodi methane.Tetra hedrobn Lett 1993;34:6379-6382

[12]C.J.Benet,F.D.Ganam,cryst.Res.Technol.29(1994)707-712

[13]B.C. Stuart. M. D. Fiet A.M Ruben chik.B.W. Shore M.D.Perry.phys.Rev.Lett.74(199502248-2251

[14]p. j. Hagrqam etal, In org. Mater 39(2000)4311-4317

[15]R.F. deFarias, Inter. j. Inorg. Mater .3(2001)303-307

[16]k.Ambujan s.selvakumar.D.Prem anand.G.Mohamed.p.sagayaraj crys.Res.techno 41(7)(2006)671-677

[17]Balakrishnan.k.Ramamurthy,cryst.Res.Techno.41(12)(2006)1184-11188

[18]'R.F.de FARIAS. Mater chem..phys .90 (2005)302-309

[19]p. mythili T.Kanagasekaran, R.Gopalakrishnan, cryst. Res.Technol 42(2007)791-797

[20]p. pideock. E. Rodrigue Z-monge L. Taylor. R. Vande streek j\&t wood P.A(2008)J. Appl. cryst $41466-470$

[21]X. chem, Titanium dioxide nano materials and their energy applications, Chinese J.catal.30 (2009)839-851

[22]S. Jin X.H.Lu,D.Wang,W.chemJ.Mol.structure.1010(2012)17-25

[23]s. pellizzeri, s.D. Delaney, T.M. korter, J.zubie ta,j.Mol.structure.1050 b(2013)27-34

[24]s.m.soliman.J.Mol.structure.1048(2013) 308-320

[25]k. senthil. s. Aravindhan A. Ruban kumar.p.G.Aravindhan,RSC.Adc.4(2014) 56112-56127

[26]s.karthiga,s.kalainathan,F.Hamada,m.Yamada,y.kondo,Rsc.Adv.6 s(2016)33159-33169 